Int. J. Dev. Biol. 57: 197-200 (2013)

doi: $10.1387 / \mathrm{ijdb} .130143 \mathrm{id}$

\title{
Testicular germ cell tumors and related research from a historical point of view
}

\author{
IVAN DAMJANOV*,1 and NICOLAI WEWER-ALBRECHTSEN ${ }^{2}$ \\ ${ }^{1}$ Department of Pathology and Laboratory Medicine, The University of Kansas School of Medicine, Kansas City, KS, \\ USA and ${ }^{2}$ Department of Biomedical Sciences, Faculty of Health Sciences, University of Copenhagen, Denmark
}

\begin{abstract}
In this brief overview of the history of testicular germ cell tumors, we touch upon the key events and personalities that have contributed to our current understanding of germ cell tumors in general, and those of the testis in particular. The intricacies of human germ cell tumor pathology and histogenesis have been elucidated in part by contributions in the field of experimental pathology and developmental biology. Correlation between clinical oncologic findings, pathology and experimental studies of germ cell tumors and related topics ushered the era of cellular and genetic engineering that have revolutionized contemporary cell and molecular biology.
\end{abstract}

KEY WORDS: history, testis, germ cell tumor, teratoma, teratocarcinoma, embryonal carcinoma, embryonic stem cell

Germ cell tumors originate most frequently in the testis and the ovaries, but they can also occur in extragonadal sites. The history of our understanding of ovarian tumors and extragonadal teratomas has been comprehensively reviewed by Pantoja and his associates (Pantoja et al., 1975; Pantoja and Rodriguez-lbanez,1976; Pantoja et al., 1976). The history of testicular teratomas and related germ cell tumors has been reviewed in the early twentiest century by Ewing (1911), and is mentioned in various chapters in several monogragraphs dealing with human tumors in general, or testicular tumors and teratomas in particular (Dixon and Moore, 1952; Masson, 1956; Pugh, 1976; Mostofi and Price,1973; Teilum, 1976; Damjanov et al.,1983; Hedinger and Dhom, 1991;Oosterhuis et al., 1991).

\section{Origin of testicular tumors}

Over 90 percent of testicular tumors are of germ cell origin. This "well-known" fact, taught as a given in all medical schools worldwide was, however, not intuitively obvious to our predecessors, who wrote lengthy dissertations and polemics about the true origin and histogenesis of these tumors. James Ewing summarized the state of confusion in his 1911 paper and discussed the seven most popular theories on the origin testicular teratomas and related tumors, which we today classify as germ cell tumors. These theories can be summarized as follows:

Theory of metaplasia

Conceived by Rudolf Virchow, this theory invoked metaplasia of the germinal cells and the stroma, postulating that the epithelial components of teratoid tumors are formed through the metaplasia of germ cells, whereas the stroma originates from the testicular stromal cells. This dual theory survived apparently only due to the enormous reputation of its originator origin.

\section{Theory of fetal inclusions}

Ewing traces this theory to Saint Donat who was the first to describe in 1696 a teratoid tumor of the testis, considering it as a "foetal monstruosity" rather than a tumor. This theory was given some credence by experimentalist $s$ who have produced teratoid tumors of the testis in mice by transplanting embryos and embryonic parts into the testes (Stevens, 1970; Damjanov and Solter, 1974)

\section{Theory of partial hermaphroditism}

Ewing credits Waldayer who suggested that the tumor of the testis are analogous to those in the ovary and that they originate from oocytes which have been misplaced into the testis during development.

\section{Theory of fertilization of the polar body}

Like the previous theory this one postulates a homology between the testis and the ovary, even though it is hard to understand how could polar bodies (normally formed during meiotic division of oocytes in the ovary) form in the testis.

Theory of isolated blastomeres

This theory Ewing (1911) credits to Marchand and Bonnet who

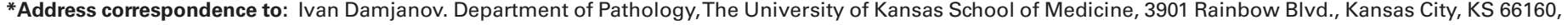
USA.Tel:+1-913-588-7090. Fax: +1-913-588-8780. E-mail: idamjano@kumc.edu
} 
have hypothesized that the tumors originate from the blastomeres segregated into the testis during embryonic development. Although it is difficult to envision a selective translocation of blastomeres into the testis, it is worth mentioning that Stevens (1970) managed to experimentally produce teratomas and teratocarcinomas from embryos transplanted into the testes of adult mice. Hence, the theory of Marchand and Bonnet has been at least partially validated.

\section{Theory of Wolffian and Mullerian duct origin}

According to Ewing (1911) this theory was championed by Cavazanni. Adenocarcinomas resembling ovarian tumors of müllerian origin have been described in the testis (Young and Scully, 1986), indicating that even this theory could be applied to some testicular tumors.

\section{Adrenal rest theory}

This theory is based on the well known presence of adrenal rests in the scrotum (Dahl and Bahn, 1962). Some adrenal rest tumors occur in the testes, but most tumors are not related to adrenal rests.

The modern view of the histogenesis of testicular tumors can be traced to the systematic studies of Friedmann and Moore (1946) performed on testicular neoplasms during the World War II. That study established beyond any doubt that over $95 \%$ of all testicular tumors in young men of military age are of germ cell origin. Experimental data obtained on mice confirmed the theory that germ cells, namely the primordial germ cells and/or gonocytes, are the cell of origin of benign and malignant teratomas (Stevens, 1967). Subsequent discovery of carcinoma in situ (Skakkebaek,1978), which is currently recognized as the precursor lesion of most germ cell tumors of the testis, proved beyond any doubt that most testicular tumors are of germ cell origin.

\section{Classification of testicular germ cell tumors}

The first modern classification of testicular germ cell tumors was formulated by Friedmann and Moore (1946), who proposed that $96 \%$ of all testicular tumors can be classified into four categories: Seminoma (germinoma), embryonal carcinoma with the subgroup of choriocarcinoma, teratoma and teratocarcinoma. This classification was refined in a slightly modified form by Dixon and Moore

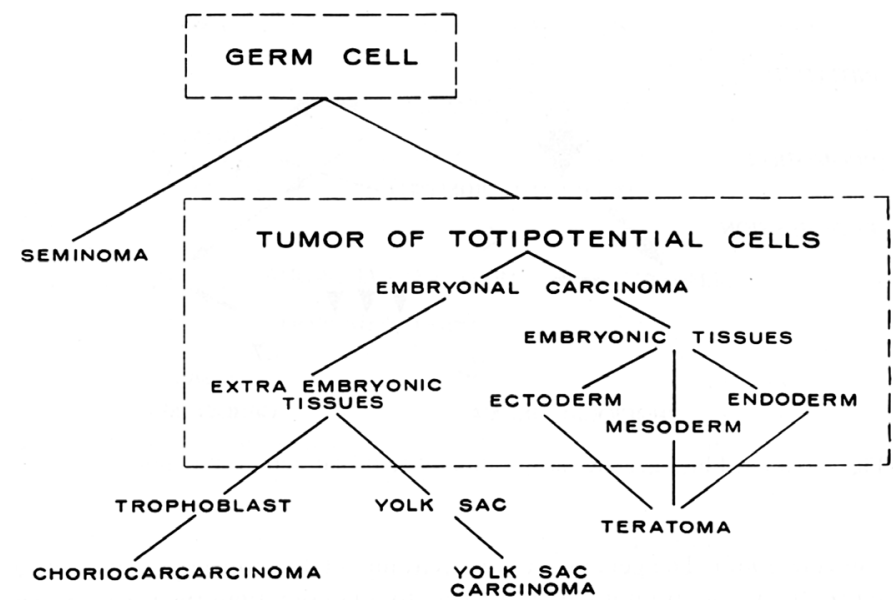

Fig. 1. Histogenesis of germ cell tumors (courtesy of G. Barry Pierce).
(1952), who published their classification in the first Armed Forces Institute of Pathology / American Registry of Pathology (AFIP) series of tumor atlases. In the AFIP atlas the germ cell tumors were divided into five groups as follows: I.seminoma, II. embryonal carcinoma, III. teratoma, IV. teratoma with embryonal carcinoma, choriocarcinoma, carcinoma or sarcoma, and V. choriocarcinoma.

The basic scientific tenet of this classification, as reviewed by Pierce and Abell (1970), holds that the neoplastic germ cells may develop into tumors along two pathways (Fig. 1): one involving abortive spermatogenesis leading to the formation of seminoma; and the second representing a caricature of embryonic development and resulting in tumors of totipotent cells, known as embryonal carcinoma cells. Embryonal carcinoma cells may form tumors composed exclusively of these cells. However embryonal carcinoma cells may also differentiate into embryonic and extraembryonic tissues thus giving rise to complex mixed tumors that contain elements of teratomas, choricarcinoma or yolk sac carcinoma.

The histogenetic classification of Dixon and Moore (1952) had some deficiencies but to a great extent it has been supported by experimental data in mice (Pierce and Abell, 1970). Nevertheless, it was considered to be too complex and was not received favorably by the andrologists and oncologists. Accordingly, the experts of World Health Organization (WHO) were charged to simplify and modify it. The team of WHO experts, led by Mostofi and Serov, proposed a morphologic classification in which they divide testicular germ cell tumors into two main categories: tumors composed of a single cell type and those composed of more than one cell type (Mostofi and Sobin 1977). At the same time a competing classification was proposed by the Testicular Tumour Panel and Registry of Great Britain (TTPR) (Pugh 1976). According to the TTPR classification the germ cell tumors were to be divided into three groups: Seminoma (comprising classical seminoma and spermatocytic seminoma), teratoma, and a mixed seminoma-teratoma group. The teratoma group comprised several subcategories, including teratoma differentiated (TD), malignant teratoma intermediate (MTI), malignant teratoma undifferentiated (MTU), malignant teratoma trophoblastic (MTT).

The current WHO classification of testicular germ cell tumors has basically retained the morphologic approach advocated by the experts of the 1977 classification (Eble et al.,2004). To facilitate comparison and avoid confusion, the WHO manual (Eble et al., 2004) provides the synonyms for various tumors and also refers to the TTRP classification, which is still used in parts of the world.

In clinical praxis in the USA it has become customary to divide the common germ cell tumors of adult testes into two main groups: seminoma and nonseminomatous germ cell tumor (NSGCT)(Fig. 2). The group of NSGCT includes embryonal carcinoma, with or without teratomatous elements, yolk sac carcinoma, and choriocarcinoma. It is of note that the term teratocarcinoma, denoting a malignant teratoma containing embryonal carcinoma cells as its malignant stem cells has been deleted from the official classifications and is today rarely used in human pathology. Nevertheless, it remains widely used in animal pathology and experimental laboratories (Solter, 2006).

\section{Experimental testicular germ cell tumors}

The systematic study of testicular tumors in mice began with the discovery of spontaneous testicular tumors in 129 mice(Stevens 

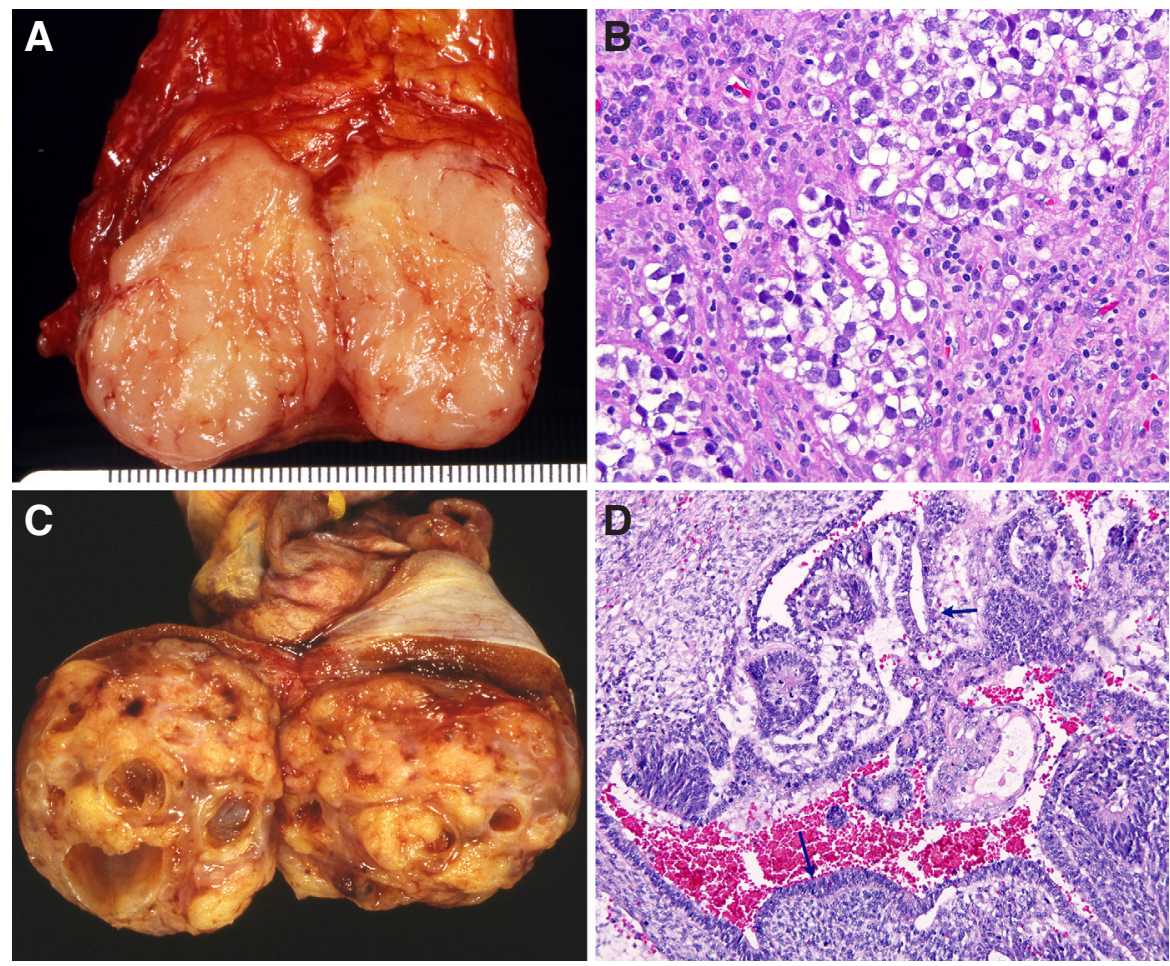

Fig. 2. Testicular germ cell tumors. (A) The seminoma has a uniform, slightly lobulated grayishyellow appearance on cross section. (B) It is composed of a single cell type. Tumor cells have a clear cytoplasm, large nuclei with prominent nucleoli, and a well defined cell membranes. Groups of cells are surrounded by fibrous septa infiltrated with lymphocytes. (C) The non-seminomatous germ cell tumor (NSGCT) appears on cross section as a partially microcystic and micronodular tumor. (D) NSGCT is histologically composed of several cell types. The malignant stem cells of NSGCTs are called embryonal carcinoma cells (arrows).

and Little, 1954). Approximately $1 \%$ of all strain 129 mice males developed teratomas, some of which turned out to be malignant and were classified as teratocarcinomas. Stevens discovered that he could increase the genetic predisposition of his mice by introducing certain genes into the original strain and developed a subline 129/ter Sv mice, which had an incidence of testicular teratomas of over $30 \%$ (Stevens, 1974). Stevens also discovered that he could produce experimentally teratomas from fetal gonadal ridges transplanted into the testis of adult mice (Stevens, 1967). Teratocarcinomas of 129 mice could be transplanted into other syngeneic animals and if injected into the abdominal cavity could produce an ascites form of the tumor (Pierce,1967). From the ascites form of retransplantable teratocarcinoma one could isolate single embryonal carcinoma cells (ECC) and that finally led to the in vitro culture of these cells (Kahan and Ephrussi, 1970). The work of Stevens and Pierce clearly demonstrated that the malignant stem cells of murine teratocarcinomas are developmentally pluripotent and can differentiate into various mature somatic tissues. Ultimately, it has been shown that the ECC can be injected into the mouse blastocyst whereupon they lost their malignancy, assumed the features of normal embryonic cells, and were incorporated into chimeric mice (Brinster, 1973).

Experimental studies of testicular germ cell tumors in mice were expanded in the 1970 to include other tumor models, most notably embryo-derived teratomas and teratocarcinoma as reviewed by Damjanov and Solter (1974). From these studies it became apparent that embryonal carcinoma cells, the malignant stem cells of testicular teratocarcinomas, have many features in common with normal embryonic cells from early stages of murine development. It has been also shown that normal embryonic cells may transform into embryonal carcinoma cells, and that the malignant embryonal carcinoma cells can lose their malignancy and assume a normal phenotype in the proper embryonic environment (like the blastocyst) which can control their malignancy (Solter, 2006). Ultimately, all these lines of research converged and led to the development of murine embryonic stem cells, chimeric and transgenic mice (Solter, 2006).

Experimental germ cell tumors have taught us a lot about normal development and neoplasia (Damjanov, 1993). What is however even more important, experimental equivalents of spontaneous testicular germ cell tumors opened new vistas and ways to study normal as well abnormal biology, health and diseases at the same time. It was hard to believe that the study of testicular germ cells tumors will ultimately revolutionize not only our concepts of cancer and developmental biology but also usher new approaches to experimental biology involving gene manipulations and genetic engineering. Nevertheless, to the surprise of even the most enthusiastic proponents, the road from teratocarcinoma to human embryonic stem cells was covered through its entire length over a relatively short period of less than 50 years during the second half of the 20th century, as recounted at the recent symposium in Cardiff in 2011 (Barbaric and Harrison, 2012).

\section{References}

BARBARIC I and HARRISON NJ (2012) Rediscovering pluripotency: from teratocarcinomas to embryonic stem cells.Cardiff,10-12 October 2011. Int J Dev Biol 56: 197-206.

BRINSTER RL (1974) The effects of cells transferred into the mouse blastocyst on subsequent development. J Exp Med 140: 1049-1056.

DAHL V and BAHN RC (1962) Abnormal adrenal cortical tissue near the testis in human infants. Am J Pathol 40: 587-591.

DAMJANOV I (1993) Teratocarcinoma: neoplastic lessons about normal embryogenesis. Int J Dev Biol 37: 39-46.

DAMJANOV I, KNOWLES BB and SOLTER D (1983) The Human Teratomas. Experimental and Clinical Biology. Humana Press, Clifton NJ.

DAMJANOV I and SOLTER D (1974) Experimental teratoma. Curr Top Pathol 59 69-130.

DIXON FJ and MOORE RA (1952) Tumors of the Male Sex Organs. Fascicles 31b and 32.Atlas of Tumor Pathology, Armed Forces Institute of Pathology, Washington.

EBLE JE, SAUTER G, EPSTEIN JI and SESTERHENN IA, Eds. (2004). World Health Organization Classification of Tumours. Pathology and Genetics of Tumours of the Urinary System and Male Genital Organs. IARC Press, Lyon.

EWING J (1911) Teratoma testis and its derivatives. Surg Gynecol 12: 230-261.

KAHAN B and EPHRUSSI B (1970) Developmental potentialities of clonal in vitro cultures of mouse testicular teratoma. J Natl Cancer Inst 44:1015-1029.

FRIEDMAN NB and MOORE RA(1946) Tumors of the testis. Military Surg 99:573-593. HEDINGER CE and DHOM G (1991) Pathologie des männlichen Genitale. Springer- 
Verlag, Berlin.

MASSON P (1956) Tumeurs Humaines. 2nd ed., Maloine,Paris.

MOSTOFI FK and PRICE EB (1973) Tumors of the Male Genital System, Atlas of Tumor Pathology, second series, Armed Forces Institute of Pathology, Washington.

MOSTOFI FK and SOBIN LH (1977) Histologic Typing of Testis Tumours. World Health Organization, Geneva.

OOSTERHUIS JW, WALT H and DAMJANOV I (1991) Pathobiology of Human Germ Cell Neoplasia. Springer-Verlag, Berlin.

PANTOJA, E. and RODRIGUEZ-IBANEZ I(1976) Sacrococcygeal dermoids and teratomas. Historical review. Am J Surg 132: 377-383

PANTOJA, E., LLOBET R and GONZALEZ-FLORES B (1976) Retroperitoneal teratoma: Historical review. J Urol 115: 520-523.

PANTOYA, E., NOY MA, AXTMAYER RW, COLON FE and PELEGRINA I(1975) Ovarian dermoids and their complications. Obst Gynecol Survey 30: 1-20.

PIERCE GB (1967) Teratocarcinoma: model for a developmental concept of cancer. Curr Top Develop Biol 2: 223-246.

PIERCE GB and ABELL MR (1970) Embryonal carcinoma of the testis. Pathol Annu 5:27-60.
PUGH RCB (1976) Pathology of the Testis. Blackwell,Oxford.

SKAKKEBAEK NE (1978) Carcinoma in situ of the testis: frequency and relationship to invasive germ cell tumours in infertile men. Histopathology 2: 157-170.

SOLTER D (2006) From teratocarcinomas to embryonic stem cells and beyond: a history of embryonic stem cell research. Nature Rev Genet 7: 319-327.

STEVENS LC (1967). Biology of teratomas. Adv Morphog 6: 1-31.

STEVENSLC (1970) The development of transplantable teratocarcinoma from intratesticular grafts of pre- and post-implantation mouse embryos. Dev Biol21:364-381.

STEVENS LC (1974) A new inbred subline of mice (129/ter Sv) with a high incidence of spontaneous congenital testicular teratomas. J Natl Cancer Inst 50: 235-242.

STEVENS LC Jr and LITTLE CC. Spontaneous testicular teratomas in an inbred strain of mice. Proc Natl Acad Sci USA 40: 1080-1087.

TEILUM G (1976) Special Tumors of Ovary and Testis, 2nd. edit. Munksgaard,Copenhagen.

YOUNG RH and SCULLY RE (1986) Testicular and paratesticular tumors and tumor-like lesions of ovarian common epithelial and müllerian types. Am J Clin Pathol 12:56-64. 


\section{Further Related Reading, published previously in the Int. J. Dev. Biol.}

Rediscovering pluripotency: from teratocarcinomas to embryonic stem cells

Ivana Barbaric and Neil J. Harrison

Int. J. Dev. Biol. (2012) 56: 197-206

Above the borderland between normal and neoplastic development

Juan Aréchaga and Ivan Damjanov

Int. J. Dev. Biol. (2012) 56: 939-948

Altered patterns of differentiation in karyotypically abnormal human embryonic stem cells

Alireza Fazeli, Chee-Gee Liew, Maryam M. Matin, Sarah Elliott, Laurent F.C. Jeanmeure, Phillip C. Wright, Harry Moore and Peter W. Andrews Int. J. Dev. Biol. (2011) 55: 175-180

Germinal tumor invasion and the role of the testicular stroma

Alejandro Díez-Torre, Unai Silván, Olivier De Wever, Erik Bruyneel, Marc Mareel and Juan Aréchaga

Int. J. Dev. Biol. (2004) 48: 545-557

Bone morphogenetic proteins (BMPs) induce epithelial differentiation of NT2D1 human embryonal carcinoma cells A Caricasole, D Ward-van Oostwaard, L Zeinstra, A van den Eijnden-van Raaij and C Mummery

Int. J. Dev. Biol. (2000) 44: 443-450

Teratocarcinoma: neoplastic lessons about normal embryogenesis

I Damjanov

Int. J. Dev. Biol. (1993) 37: 39-46

Ontogeny, pathology, oncology

V E Papaioannou

Int. J. Dev. Biol. (1993) 37: 33-37

Visceral yolk sac-derived tumors

H Sobis, A Verstuyf and M Vandeputte

Int. J. Dev. Biol. (1993) 37: 155-168

Two proto-oncogenes that play dual roles in embryonal cell growth and differentiation E D Adamson

Int. J. Dev. Biol. (1993) 37: 111-116

Strife in the germ line

C F Graham

Int. J. Dev. Biol. (1993) 37: 25-31

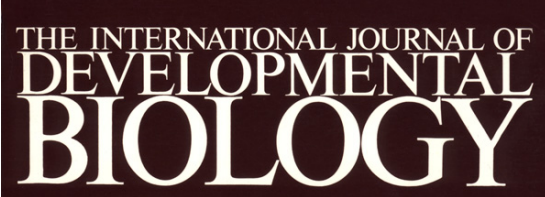

Volume 37 No.1

March 1993

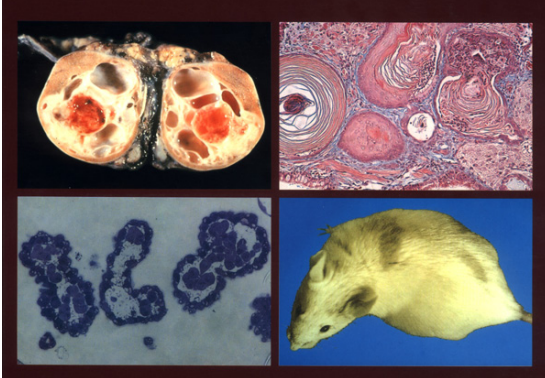

Developmental Aspects of Neoplasia
5 yr ISI Impact Factor (2011) $=2.959$

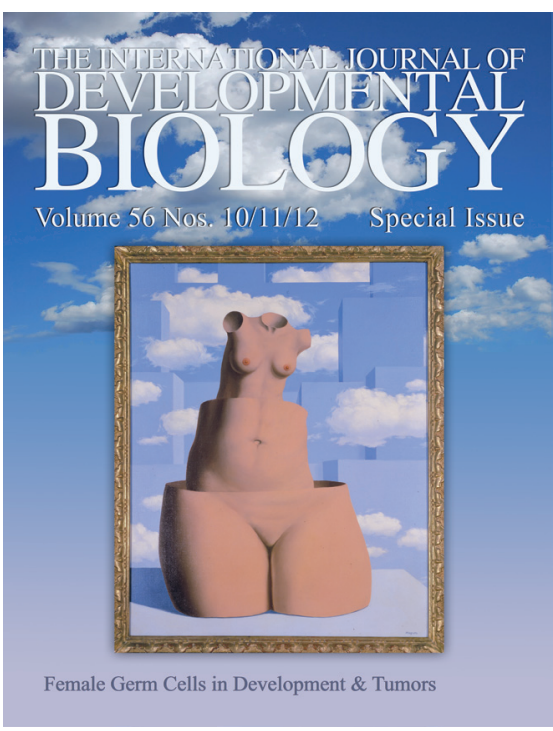

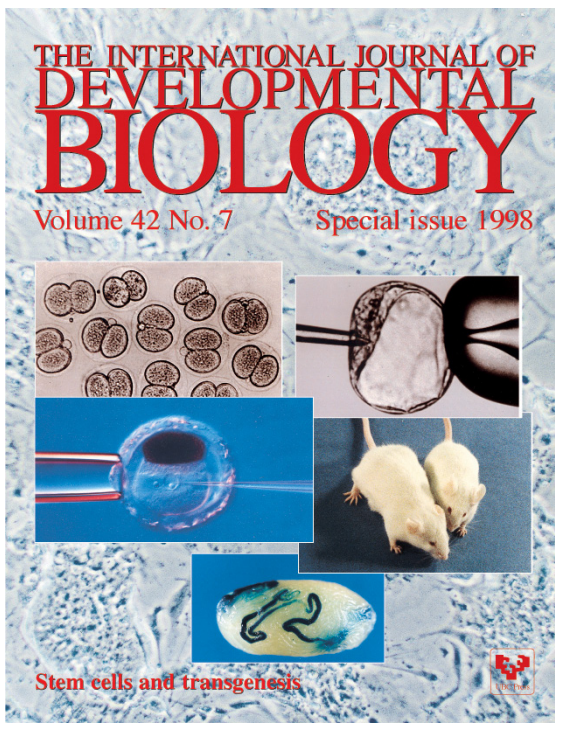

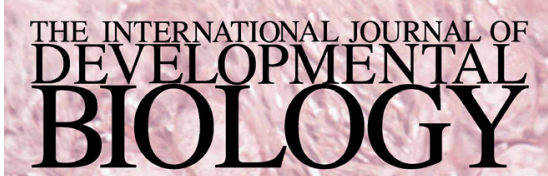

Volume 45 No. $3 \quad$ Special issue

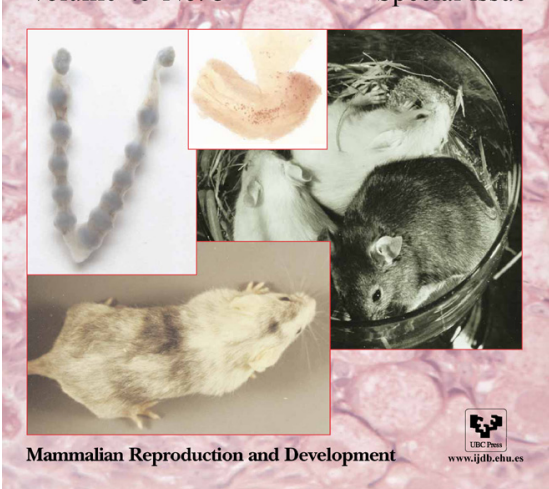

